\title{
What if everyone becomes a sharer?: A quantification of the environmental impact of access-based consumption for household laundry activities
}

Raphael Wasserbaur, Tomohiko Sakao, Maria Ljunggren Söderman, Andrius Plepys and Carl Dalhammar

The self-archived postprint version of this journal article is available at Linköping University Institutional Repository (DiVA):

http:// urn.kb.se/ resolve?urn=urn:nbn:se:liu:diva- 165771

N.B.: When citing this work, cite the original publication.

Wasserbaur, R., Sakao, T., Ljunggren Söderman, M., Plepys, A., Dalhammar, C., (2020), What if everyone becomes a sharer?: A quantification of the environmental impact of access-based consumption for household laundry activities, Resources, Conservation and Recycling, vol 158, article 104780. https:// doi.org/ 10.1016/j.resconrec.2020.104780

Original publication available at:

https:/ / doi.org/ 10.1016/j.resconrec.2020.104780

Copyright: Elsevier

http:// www.elsevier.com/

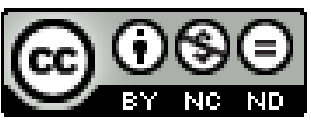




\title{
1 What if everyone becomes a sharer?
}

2 A quantification of the environmental impact of access-based

3 consumption for household laundry activities

4

5

6

7

8

\author{
Raphael Wasserbaur ${ }^{*}, 1$, Tomohiko Sakao ${ }^{1}$, Maria Ljunggren Söderman ${ }^{2}$, Andrius Plepys ${ }^{3}$, Carl Dalhammar ${ }^{3}$ \\ ${ }^{1}$ Division of Environmental Technology and Management, Department of Management and Engineering, \\ Linköping University, Sweden \\ ${ }^{2}$ Division of Environmental Systems Analysis, Chalmers University of Technology, Sweden \\ ${ }^{3}$ The International Institute for Industrial Environmental Economics, Lund University, Sweden
}

Highlights

- System dynamics model for transitions from owning to sharing with GHG emissions

- Sharing of laundry facilities has considerable potential in EU countries

- Sharing may save more GHG emissions in countries with higher energy carbon intensity

\begin{abstract}
In order to meet the EU's climate and resource efficiency targets, changes in our daily-life behaviours, as well as business models, are urgently necessary. More insights are needed to make real changes based on research with a systems perspective. We developed a system dynamics model to analyse the environmental benefits of a transition from ownership-based to access-based household laundry activities. The model considers demographic, technological and behavioural aspects and thereby assesses the environmental impact of laundry activities. The model is applied to the Swedish as well as the European context and allows cross-country comparisons. The results indicate a significant potential of the sharing economy. The higher utilisation of shared machines and extended lifespans of the machines can cut greenhouse gas emissions by a third and lower raw material usage overall and lower primary raw material in production due to higher recycling rates. The carbon intensity of the energy mix is a crucial factor for the environmental consequences that arise through changes in energy usage due to sharing economy practices. This case study shows the value of adopting policies that could promote sharing and extended life spans.
\end{abstract}

Keywords: sharing economy; access-based consumption; washing machine; system dynamics; environmental impact analysis.

\section{Introduction}

The transition towards a more sustainable future, where humanity operates within the planetary boundaries, is one of the major challenges of our time. The sharing economy (Parente, Geleilate, \& Rong, 2018) can help alleviate the current economy's resource consumption. It can potentially increase the utilisation intensity of products by avoiding each person having to own a product for the fulfilment of one's needs (Byers, Groth, \& Sakao, 2015).

A fair amount of literature on direct environmental impacts of the sharing economy revolves around transportation, accommodation, and small consumer goods. Several meta-reviews of the environmental impacts of sharing are available, for example, for car-sharing schemes (Chen \& Kockelman, 2016; Jung \& Koo, 2018), tools or clothes (Skjelvik, Erlandsen, \& Haavardsholm, 2017) or the entire peer-to-peer sharing 
platform mediating the sharing of everyday items like skis, electric tools, cars, video games, bicycles and cooking equipment (Martin, Lazarevic, \& Gullström, 2019).

Most of the studies identify different contextual environmental benefits from sharing solutions, which are mainly due to savings from avoided production or more efficient use of shared assets over their productive lifetime. (Ala-Mantila et al., 2016), for instance, stress the benefits of collaborative consumption among solo-dwellers to reduce greenhouse gas (GHG) emissions of small-sized urban households. (Underwood \& Fremstad, 2018) find that sharing within households leads to decreasing transport-related emissions and residential energy use.

Inherent to most households in European countries are washing machines (WMs), which in the EU account for the largest share of household appliances by mass. Annually, about $1.4 \mathrm{Mt}$, or $22 \%$, of the total mass of all household appliances brought to the EU's market are new WMs with the current stock estimated at 191.9 million (Huisman et al., 2018). This means that a majority of European households has their own WM (Pakula \& Stamminger, 2010). Although WMs are fairly expensive, they are largely underutilised with long idling times (Pakula \& Stamminger, 2010; Saccani, Perona, \& Bacchetti, 2017). Effective sharing of such idling appliances can generate economic savings for households and free the increasingly expensive space, which is a lucrative opportunity for both property owners and real estate developers. However, there are little signs that sharing strategies win over product ownership and the existing solutions for shared access to laundry facilities seems to be in decline in many cities. Better understanding of the benefits from resource efficiency improvements through sharing can bring another perspective to support the decisions.

Little of previous work touches on the transitional dynamics and environmental implications of shifting from ownership-based to access-based consumption of laundry activities and WMs in particular. Borg \& Högberg (2014) point to a decrease of shared communal laundry facilities in Sweden and the environmental disadvantages of individual ownership of WMs to shared laundry facilities. Shahmohammadi et al. (2018) present a cross-country study about the drivers of the variability in life cycle GHG emissions of WMs. (Retamal \& Schandl, 2017) compare the resource consumption of different forms of laundry in a developing country context, and Stamminger (2011) develops a generic model for the resource consumption for laundry in households but stays with the analysis on the product level.

With a focus on the sharing economy, this paper aims to advance the body of knowledge by proposing a dynamic simulation model that touches upon multiple aspects, including user behaviour, technological development, policy role, and environmental impact. A dynamic approach offers a contrast to many of the existing static and descriptive studies and can show how the underlying system evolves over time.

We are, in particular, interested in how the environmental impact changes if large parts of the population start to engage in shared laundry practices and what are the important factors determining the impacts. The research goal is to assess the potential environmental consequences of the large-scale implementation of access-based consumption as an alternative to ownership-based consumption of WMs. The object of study is household laundry practices with WMs at the core of the analysis. The following research question is formulated:

RQ: What are the environmental consequences of a shift from individual ownership-based to access-based consumption for home laundry activities in multi-family housing?

The remainder of this paper is as follows. In Section 2, we provide background information including policy, design and business model aspects around WMs. Section 3 explains the system dynamics model that we developed. Section 4 then discusses the usefulness of the model by presenting the simulation results, and in particular, a comparison between a Swedish and the European average parametrisation. Finally, Section 5 concludes the paper. 


\subsection{Sharing, collaborative consumption and access-based consumption}

The terms sharing, collaborative consumption and access-based consumption are three concepts that are used to classify certain sharing activities. Sharing has a joint sense of ownership, like in a family, where household items are shared with no single person to be the sole owner (Bardhi \& Eckhardt, 2012). Accessbased consumption can be defined around six dimensions (Bardhi \& Eckhardt, 2012):

- Temporality: consumers use a product only for a limited time.

- Anonymity: consumers use an object independently from each other. Interactions with other consumers using the same object may vary.

- Market mediation: objects are mediated through a third party. This may be based on profit (e.g. Airbnb) or not-for-profit considerations (e.g. library).

- Consumer involvement: consumers experience a differing degree of involvement in the provision of an object, e.g. maintenance or delivery of objects.

- Type of accessed object: the object may be used for the experience it holds, e.g. entertainment, or for the functionality it can bring. The object may be on a spectrum from digital (e.g. movies) to material (e.g. tools).

- Political consumerism: consumption may be used more or less as a form of expression, commitment or other political tool.

Collaborative consumption is a peer-to-peer-based sharing of underutilised products and services facilitated through community-based online services (Belk, 2014). Belk (2014) sees collaborative consumption as a subset of access-based consumption. It exhibits some level of market mediation. Popular examples of related sharing economy business models that focus on unlocking the value of unused assets through online platforms are Airbnb, eBay and Uber (Parente et al., 2018).

In the communication "A European agenda for the collaborative economy" (European Commission, 2016), the European Commission presents its understanding of the sharing economy. The collaborative economy, as the sharing economy is called, involves three types of actors: service or asset providers, who share resources; users, who use or access the resources; and intermediaries. This is in line with Belk's definition, that "Collaborative economy transactions generally do not involve a change of ownership and can be carried out for profit or non-profit." (European Commission, 2016, p.3). In this paper, dealing with WMs as a case, the nuanced differences between these terms are not critical; sharing and accessing are used interchangeably, prioritising the readability.

\subsection{Business models in the WM industry}

For a few decades already, authors have tried to argue for a function-based economy (Mont, 2002; Stahel, 1994). A crucial advantage of such an economy is that the logic of economic success is not based on material throughput, but on functionality delivered or needs fulfilled. Products can be delivered to multiple customers, increasing utilisation and preventing the need for each person to own material goods (Martin, 2016). A business model can play a key role in utilisation; it defines how a company creates, delivers and captures value (Teece, 2010). The most common business model in the WM industry is sales-based. Households are purchasing machines and using them for a given time before disposing of them. When looking at the utilisation of privately-owned WMs, it seems ownership is the "enemy" of utilisation. In Western Europe, most households own a WM and are the single user with an annual average of 167 wash cycles (Pakula \& Stamminger, 2010). Assuming an average duration of a wash cycle of less than two hours (Alborzi, Schmitz, \& Stamminger, 2017a), WMs are used 330 hours a year, resulting in a utilisation rate of approximately $4 \%{ }^{1}$. Other, service-based business models, also lead to a de facto ownership-level utilisation.

\footnotetext{
${ }^{1}$ A theoretical utilisation rate of actual utilisation over potential utilisation: $\frac{330 \text { hours }}{24 \text { hours } * 365 \text { days }}=4 \%$.
} 
For example, Homie, a Dutch company, offers WMs through a pay-per-use model with pricing based on the degree of sustainability of the washing behaviour. The pricing model incentivises households to wash fewer times, with colder temperatures and fuller loads (Bocken et al., 2018). An additional example is BlueMovement (Bosch, 2018), an offering that leases WMs to private customers. After the first term of the lease, the WMs return to the original equipment manufacturer and can be reused. Currently, service-based offerings in general seem to be based on conventional machines, the design adaptations apparently do not exceed the level of conventional offerings, and adaptations are mostly aimed at service and less on product aspects. These kinds of service-based business models seem to be quite novel in the retail WM industry in terms of ownership structure. Yet, they shouldn't be neglected. Service-based offerings can contribute to a circular economy by improving resource efficiency (Sakao, Wasserbaur, \& Mathieux, 2019).

There are also business models that facilitate access-based consumption of WMs, such as communal laundry rooms (Mont \& Plepys, 2007) or launderettes (Amasawa et al., 2018). Both are access-based, allowing users only to use the functionality of WMs and not to own them. Launderettes are self-service laundry businesses typically seen in densely populated urban areas where living space is relatively expensive. The machines have a long life and high durability, with multiple users accessing them. Communal laundry rooms are facilities that are commonly accessed by the tenants of a building of flats and are managed by the housing companies (Electrolux, 2019; Mont \& Plepys, 2007). Payments are usually included in the rent, and the scheduling can be via the internet, mobile phone applications or non-virtual means like noticeboards. A third, rather theoretical option for commercially accessing WMs is peer-to-peer rental. WM owners may grant free capacity of their WMs through apps or other forms of personal communication.

For the remainder of this paper, we will group the business models according to the ownership status of WMs. We assume that business models either lead to ownership-based (e.g. the above-mentioned salesbased or product-based offerings) or access-based (e.g. launderettes or communal laundry facilities) consumption.

\subsection{Governmental policies affecting environmental performance}

There are several important policies that regulate the product market of WMs in the EU. The EU Ecodesign Directive aims to improve the water and energy efficiency of WMs, and the recently adopted and updated ecodesign requirements for WMs introduce new requirements to change product design and reparability in order to save resources (European Commission, 2019). For instance, it prescribes WM producers to give professional repairers access to certain spare parts, for a minimum of 10 years after placing the last machine on the market (Cordella, Alfieri, \& Sanfelix, 2019). The EU Energy Labelling Directive (European Commission, 2010a) requests manufacturers to inform customers about the products' energy performance. This nudges producers to design efficient products, as it appeals to the customers' environmental awareness (Sammer \& Wüstenhagen, 2006). Current policies also require new WMs to have at least one washing programme running at $20^{\circ} \mathrm{C}$ (European Commission, 2010b), as lower water temperatures are effective in decreasing energy usage (Morgan, Foxon, \& Tallontire, 2018).

Taking a national example of laundry-related policies, Swedish building regulations traditionally foresaw to have communal laundry rooms for tenants in multi-family buildings. In Sweden, since the 1950s and 60s communal laundry rooms became a regular part of multi-family building plans (Lund, 2009). However, recently Borg and Högberg (2014) observed trends among developers of new multi-family buildings to move away from the concept of communal laundry towards solutions with an individual WM for each household.

Both at the EU and the national level, there are new policies related to the circular economy, including policies to combat planned obsolescence, open up the repair sector and make repair more attractive to consumers (Maitre-Ekern \& Dalhammar, 2016). In addition, some policies for the sharing economy are being adopted by local governments at the city level (Martin et al., 2019). However, generally, policies to 174 support the sharing economy are fewer - as the developments are understood to be driven naturally by 
economic incentives - and these are of a "softer" nature involving more encouragement and support, rather than regulation or taxes (SOU, 2017).

\subsection{Design options for improving environmental performance}

The most relevant design options to improve the environmental impact of WMs mainly affect the use phase, i.e., the consumption of water and detergent as well as electricity usage. The largest potential for energy improvements regards the decrease in the average wash temperature and optimal user behaviour (Schmitz $\&$ Stamminger, 2014). There are several known design options to increase use phase efficiency, of which some are partly implemented in premium models. Examples include brushless AC motors; cold wash and complex mechanical action programmes; electronic controls to optimise detergent and water use, rinsing and spinning; hot water supply of external sources instead of heating the water up in the machine; substitution of potable water by rainwater, automatic detergent dispensing systems, steam cleaning for less water usage, and programme optimisation; and nanotechnologies that can achieve hygiene functionality at low temperatures (Barthel \& Götz, 2013; Boyano et al., 2017). A repair service-based statistic, provided by an Austrian repair shop, unveils that electronics, shock absorbers and bearings, door components, and carbon brushes make up the majority of failures in WMs (Tecchio, Ardente, \& Mathieux, 2016). These parts are priority parts for lifespan-extending measures for household WMs (Cordella et al., 2019).

\section{Method and model}

\subsection{Overview}

System dynamics (SD) is the selected method for this study, as it allows to model complex system structures and simulate dynamic behaviour (Sterman, 2000). In SD, stocks represent variables that accumulate or dissipate over time. The changes in these stocks are realised by flows. Feedback is understood as circular causal loops that either have self-reinforcing or balancing behaviour (Sterman, 2000). Typically, an SD model consists of a set of phenomena or processes that are by themselves relatively easy to understand. Complexity can emerge when these phenomena are interlinked and simulated over time. Often, the specific value of such models lies not just in showing the systems' dynamics but also in exposing new system behaviour that was not obvious by analysing the single phenomena (Davis, Eisenhardt, \& Bingham, 2007).

This study looks at the environmental impacts of accessing of WMs compared to individual ownership. Our SD model considers demographic growth, technological development, and behavioural aspects as well as the related emissions of carbon dioxide equivalents $\left(\mathrm{CO}_{2} \mathrm{eq}\right)$. The analysis focusses on the laundry practices of the population in multi-family housing. The model was formulated based on a review of the WM-related and sharing economy literature, as well as interviews with industry actors. The model was developed with Vensim PLE Plus for Windows version 8.0.4. The SD model consists of three sub-models: the population model, the use phase model and the emissions model; the respective stock-flow diagrams can be found in the appendix.

\subsection{Population model}

The population model captures the basic demographic development in multi-family housing. We assume that only households in multi-family buildings are relevant for sharing of laundry facilities. Due to living space limitations and higher population density, they are much more likely to consider whether to own or share laundry equipment. Therefore, the population's households are split into sharers and owners (see Figure 1). Sharing households access WMs, whereas owning households privately own WMs. Both of these household stocks increase according to their relative size and by publicly available population growth rates.

The stocks of WMs increase relatively with the households using them. For every owning household, a new WM is added to the stock. The stock of shared WMs also grows with the sharing households but at a slower rate, as multiple sharing households access one WM. WMs break down at the end of their lifespan; the lifespan is measured in wash cycles instead of years. Assuming a WM can perform a maximum number of 
wash cycles before it becomes obsolete, it is the utilisation that determines the time a machine is in use. In the case where a WM becomes obsolete, a window of opportunity opens for a household to change its behaviour from owning to sharing. This sub model is inspired by the Bass diffusion model (Sterman, 2000), but works differently from it. The causal loop diagram in Figure 1 describes these dynamics.

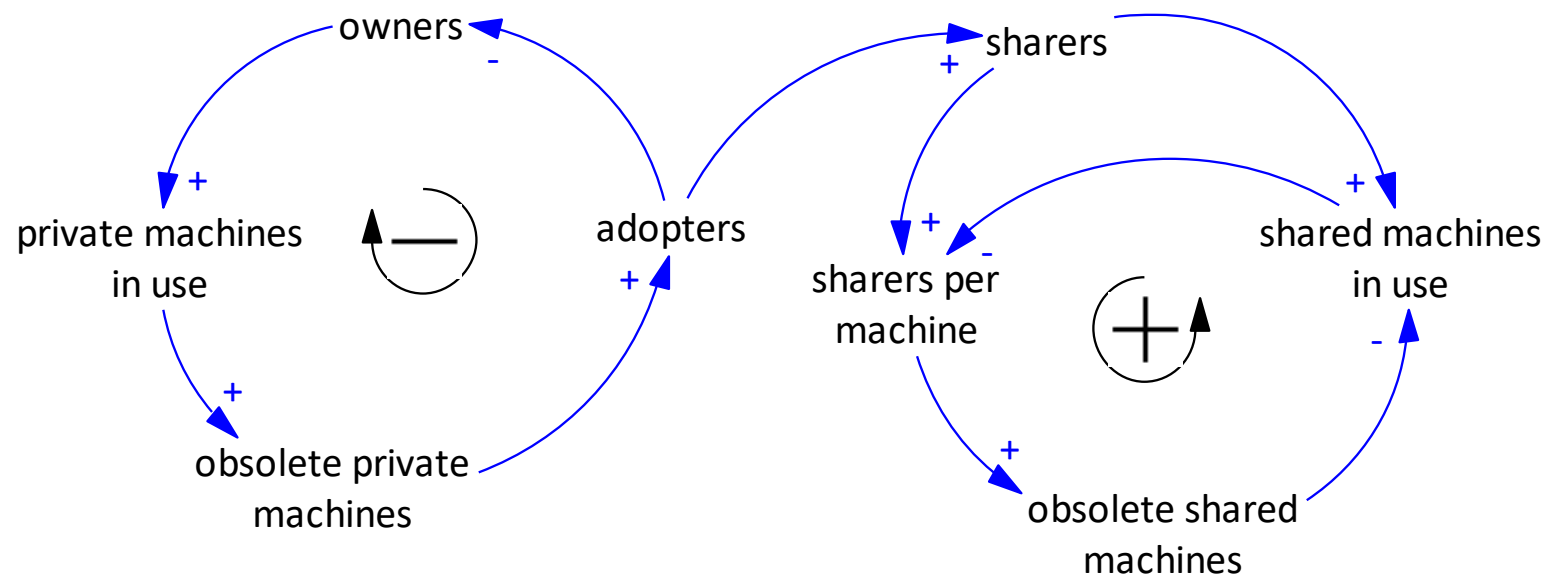

Figure 1. Causal loop diagram showing the model's internal feedback loops. The population is split into owners and sharers. Owners have private machines in use, once they become obsolete, a part of the owners adopts sharing behaviour and shifts to sharers, whereas the rest remains owners. The more sharers, the more people have to share a given amount of machines. The number of shared machines in use grows in relation with the amount of sharers. The utilisation is determining how quickly machines become obsolete. The more shared machines in use, the less sharers per machine. See the appendix for the stock-flow diagrams.

\subsection{Use-phase model}

The use-phase model simulates detergent consumption and energy usage during the use phase. Several data points regarding the life cycle impact of WMs are taken from existing data material (Boyano et al., 2017). During the use phase, the user behaviour determines the usage of electricity and detergents.

User behaviour can have a significant impact on the water and detergent consumption as well as the energy usage of a WM (Alborzi et al., 2017a; Schmitz \& Stamminger, 2014). Alborzi et al. (2017a) have shown that laundry user behaviour differs between European countries; laundry behaviour is measured by variables such as frequency of used programmes, load rates, type of laundry care or wash cycles per week. We assume user profiles that depend on the household size and whether the households are sharing or owning WMs.

Due to technological improvements and policy requirements, new machines are more efficient; every new machine reduces the average consumption of the entire WM stock. The diffusion of the efficiency improvements in the stock depends on the replacement rate of the old machines (see also Figure 4). Considering that a WM's lifespan is approximately 3,000 wash cycles, the time scale is an important aspect. The parameter electricity usage of a new washing machine reflects technological improvement throughout the simulations. The parameter value decreases over the years and it expresses the electricity used for an average wash cycle in kilowatt hours (Boyano et al., 2017).

\subsection{Emissions model}

The emissions model adopts a life cycle perspective, including production, the use phase and end-of-life (EoL) management of WMs (see ). Earlier works have shown that the use phase is the major contributor to life cycle emissions of WMs (e.g., (Shahmohammadi et al., 2018)). Production includes emissions caused by raw material extraction and manufacturing, while use phase emissions are determined through the use of electricity and detergents. The EoL management phase leads to savings of emissions associated with avoided raw material extraction through recycling. Due to the low contribution, packaging and distribution are not considered (Boyano et al., 2017). 
Production and EoL-related processes are assumed constant throughout the simulation period, whereas

decarbonisation of the energy mix over the next decades (EEA, 2017), as well as technological improvements that lead to higher energy efficiency of WMs (Barthel \& Götz, 2017; Boyano et al., 2017), are included. The bigger mass of shared (larger and better quality) WMs is accounted for by considering a higher resource consumption, a heavier emissions impact in production as well as respective savings at the EoL. In addition, as shared WMs are typically operated by commercial or other formal entities, i.e. launderettes or communal laundry facilities, we assume a $100 \%$ collection rate. Private WMs are collected to a lesser degree and depend on national levels (Eurostat, 2019b).

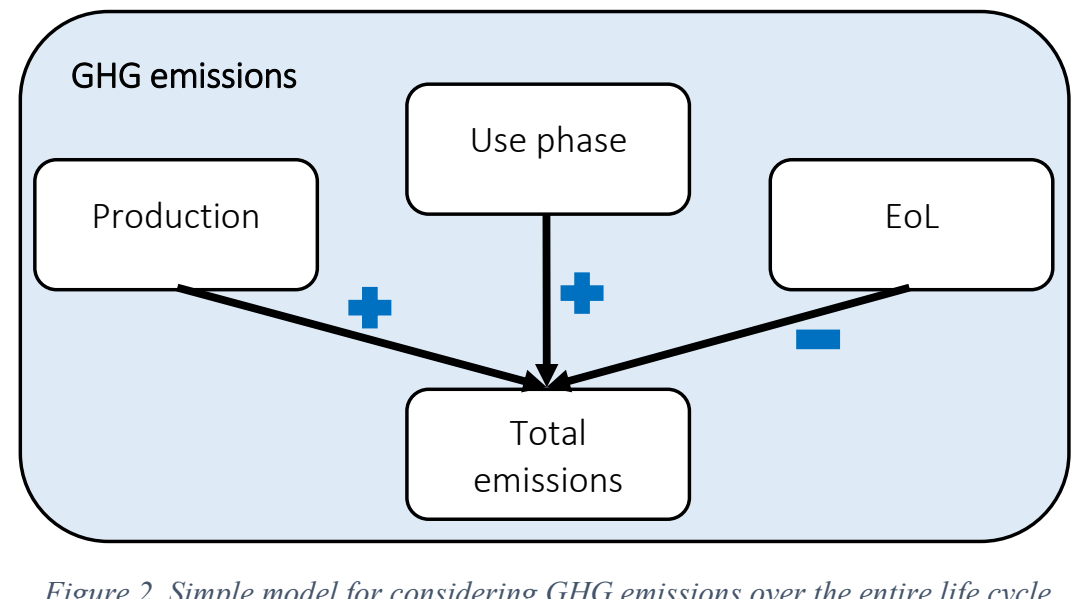

\subsection{Model validation}

In a strict sense, SD models cannot be validated, but their usefulness can be shown (Sterman, 2000). The model development followed SD modelling guidelines (Rahmandad \& Sterman, 2012). In this regard, multiple tests were conducted to gain confidence in the model results. The purpose of the model is to show changes in resource consumption and emissions in case more people adopted sharing behaviour. We drew the system boundaries around households and the used washing machines, whereas changes in behaviour are covered by scenarios.

Testing included extreme parameter value testing, where parameters are set to very high or low values to see if the model exhibits illogical behaviour. The model was tested for time step adequacy, with one day as the smallest time step, as well as for integration error using two different integration methods (Euler and Runge-Kutta), with no significantly different results for both tests. As the model is used to analyse the novel behaviour of households shifting to shared laundry activities, behaviour reproduction tests were omitted. A unit test has been conducted, showing the consistency of the variables' dimensions and units. Parameters are consistent with the real world.

In order to find the system's hotspots, a univariate sensitivity analysis was conducted, where one parameter is increased by up to $100 \%$ and decreased by up to $50 \%$, while the other parameters are kept at the reference level (see Table 1). This procedure has been performed for each parameter, and for all three scenario types that are described in the following section. In order to depart from an equilibrium state during sensitivity testing, population growth was assumed to be zero.

The accumulated GHG emissions over the studied period were fairly sensitive to two parameters: both, average household size and detergent use per wash had a strong effect on GHG emissions when being increased by $100 \%$. The effect of the household size is not surprising. Household size increases the wash frequency per household, and in turn, leads to machines becoming obsolete faster. Even though household size may be a hotspot, it is not a critical parameter as it has not changed much in the last decades and is not expected to do so in the future (1.9 people per household in Sweden (Statistics Sweden, 2019), and 2.3 for EU average (Eurostat, 2018a)). Detergent use per wash is partly determined by the washing machines' 
specifications and partly by user behaviour. The sensitivity of the environmental impact of laundry activities to behavioural aspects has also been shown in earlier works (Pettersen, Boks, \& Tukker, 2013).

The results of a washing process depend on the combination of washing time, mechanical work, wash temperature and chemical application (Alborzi, Schmitz, \& Stamminger, 2017b). Due to the trends in policy making to encourage a reduction of the average wash temperature in the coming years, the relative contribution to environmental impacts of detergents will increase. Therefore, we do not assume a decrease in detergent use but rather constant levels throughout the simulation period, unlike energy use, which is assumed to decrease.

\subsection{Scenarios}

Sweden and the EU average serve as cases for the scenario setting. Compared to other industrialised countries (Pakula \& Stamminger, 2010), Sweden has a relatively low household ownership rate of WMs. Approximately $25 \%$ of all households do not own a WM (Statistics Sweden, 2009), although practically every person can afford a WM (Eurostat, 2018b). This number has declined slightly from 1990 until today but remains at a relatively high level. The low ownership rate goes back to a long tradition of sharing of communal washing centres and a right for everybody to have clean clothes (Lund, 2009).

On the other hand, the ownership level of the EU average is higher than in Sweden. Several countries in the EU exhibit more than 95\% ownership rates (Pakula \& Stamminger, 2010), and the EU average is at $89 \%$ (see calculations in the appendix). The usage of WMs differs quite a bit between countries. Sweden has a frequency of 140 wash cycles per household per year, while the EU average is at 167 (Pakula \& Stamminger, 2010).

Eurostat population projections (Eurostat, 2015) suggest an average annual population growth of $0.7 \%$ for Sweden until 2049 and only $0.08 \%$ for the EU average. According to these projections, the demographics in European countries are fairly heterogeneous. The overall European population reaches a peak at around 2040, after which it decreases. In Sweden, the population is projected to grow continuously until the year 2100. The average living area per person has slightly decreased over the last years, and the household size in multi-family housing is 1.9 persons per household. For the sake of comparability, in EU-average scenarios the same population size is used as for the Swedish scenarios. Looking at the distribution of the population by dwelling type in Sweden, approximately 44\% (2.0 million households) live in single-family housing and $48 \%$ (2.2 million households) in multi-family housing. Throughout the EU, $42 \%$ of the population lives in multi-family housing (Eurostat, 2019a).

In line with publicly available data (Statistics Sweden, 2009; Zimmermann, 2009), we assume a 50\% ownership rate for WMs of households in multi-family buildings in Sweden. Previous work estimates that there are 30,000 communal laundry facilities in multi-family buildings, with 200,000 shared machines. Therefore, the 1.1 million non-owning households have access to 200,000 machines (Borg \& Hogberg, 2014), or 5.5 households per shared WM. For the EU average, our calculations indicate a higher ownership rate of $73.8 \%$, which translates to 1.62 million owners and 567,000 sharers. Due to a lack of data, we will assume the same access rate of 5.5 households per shared WM for the EU average.

For analysing the environmental impacts of the sharing of laundry facilities, the national electricity mixes are important as the biggest impact happens during the use phase of a WM's life cycle. In 2018, the carbon intensity of the electricity consumed in Sweden was the lowest of the entire EU at $47 \mathrm{~g} \mathrm{CO}_{2} \mathrm{eq} / \mathrm{kWh}$ (Moro \& Lonza, 2018), whereas the European average was at $306 \mathrm{CO}_{2} \mathrm{eq} / \mathrm{kWh}$. Forecasts of carbon intensities were used during the simulation period.

Departing from this statistical background, three "what if" scenarios are developed. The scenarios are simulated for the time frame 2019 - 2049 to assess the differences in the environmental impacts between access-based and ownership-based consumption for household laundry activities. The first scenario reflects the status quo with the continuation of current sharing practices, the second scenario assumes that $50 \%$ of owners become sharers, and the third scenario assumes a $100 \%$ sharing behaviour adoption rate. We assume 
that owners consider shifting to access-based consumption when their machines become obsolete, i.e. when the WMs are at the end of their lifespan. The simulations start from a state in which the WM stocks are well mixed, i.e. washing machines with varying remaining lifespans. The comparison between Sweden and the EU shows, on the one hand, the usefulness of the SD model in comparing different contexts, and on the other, the varying importance of parameters depending on the country context.

\subsubsection{Status quo}

This scenario assumes a perpetuation of the status quo of the current ownership structure of WMs and serves as a baseline for the simulations. Borg and Högberg (2014) have indicated that there is a trend in current building practices in Sweden away from communal laundry facilities towards placing individual WMs into each household. This indicates that the status quo scenario might already be an optimistic scenario in terms of ownership levels. In Sweden, approximately $50 \%$ of the households in multi-family buildings have their own machines, whereas the remainder uses shared machines.

Sharers are assumed to wash differently than owners. Due to limited accessibility, they wash less frequently, and, given the same laundry needs, they load the WMs with more laundry per wash cycle. This decreases the annual number of cycles from the current 140 (167 for EU) per household to 100. Moreover, shared WMs have a higher efficiency per load as their capacity is larger. Furthermore, we assume that the lifespan of WMs designed for communal laundry facilities remains at a level of 30,000 cycles (Electrolux, 2018) throughout the simulations.

\subsubsection{0\% become sharers}

In the " $50 \%$ become sharers" scenario, we investigate a hypothetical case where sharing advances significantly compared to the status quo scenario. In this scenario, the growth of sharing households depends on the obsolescence rate of private WMs. In 50\% of the cases, when a machine becomes obsolete, instead of buying new machines, households decide to shift their behaviour to access-based consumption. The relevance of events such as breaking down of equipment, moving into other areas for living, or new infrastructure for shifting one's behaviour has been described in earlier work (Amasawa et al., 2018). As there is population growth, both stocks of sharers and owners will still increase, yet the stock of sharers grows relatively stronger.

\subsubsection{0\% become sharers}

In this extreme scenario, we investigate the question, "what if everyone becomes a sharer?" when old machines become obsolete. In this scenario, from the first year on, all owners whose WMs break down switch to become sharers, and all new households that emerge due to population growth become sharers as well.

\section{Results and discussion}

\subsection{Initialisation of the model}

This work explores changes in GHG emissions that are related to a transition from ownership-based to access-based laundry activities. The analysis focusses on the fulfilment of laundry needs of a population living in multi-family housing, in this case, the necessary washing machines and associated GHG emissions.

The model simulations were based on two sets of parameters: one for Sweden and one for the EU average. In the status quo scenario, the levels of private ownership of WMs stay the same. The production of new WMs remains at high levels; it is driven by the replacement of the existing WM stock, as well as new households that emerge naturally from the population growth. The second scenario assumes that $50 \%$ of owners turn to sharers. As a consequence, the percentage of WM sharers increases dramatically, to around $75 \%$ of the multi-family housing population by the end of the simulation period. The growth of the group of sharing households depends on the obsolescence rate of private WMs. In the third and rather idealistic scenario, every WM-owning household becomes a sharer after the WM becomes obsolete. No new private 
380 WMs are added, while the stock slowly depletes as the machines break down. For the sake of comparability 381 between the Swedish and the EU average parametrisation, all simulations' initial population equal the 382 Swedish population living in multi-family housing of 2.2 million households.

383 Table 1. Initial values for the simulation sets.

\begin{tabular}{lc||c}
\hline \multicolumn{1}{c||}{ Sweden } & EU average \\
\hline $\begin{array}{l}\text { Energy carbon intensity in 2019 } \\
\text { [g CO} 2 \text { eq/kWh] } \\
\text { source: (Moro \& Lonza, 2018),(EEA, 2019) }\end{array}$ & 47 & 306 \\
\hline $\begin{array}{l}\text { Annual population growth rate [\%] } \\
\text { source: (Eurostat, 2015) }\end{array}$ & $0.70 \%$ & $0.08 \%$ \\
\hline $\begin{array}{l}\text { Wash cycles per household } \\
\text { [cycles/household/year] } \\
\text { source: (Pakula \& Stamminger, 2010) }\end{array}$ & 140 & 167 \\
\hline $\begin{array}{l}\text { WM collection rate [\%] } \\
\text { source: (Eurostat, 2019b) }\end{array}$ & 0.55 & 0.41 \\
\hline
\end{tabular}

\subsection{Simulation results}

The "100\% become sharers" scenario shows the lowest levels of GHG emissions (Table 2). In the Swedish case, access-based consumption results in a $29 \%$ reduction of the total GHG emissions compared to the status quo, and in the European case, a 35\% reduction. The gap between the Swedish and European starting values (see the gap between the two groups of lines inFigure 3 ) is explained by the different initialisations.

The fact that sharing can be so beneficial in Sweden despite relatively low energy carbon intensity shows that the impact of non-electricity factors like product materials and detergents is quite important. The difference spreads (Figure 3) within the two groups also show that with EU conditions, sharing could have a larger relative impact on GHG reductions than in Sweden.

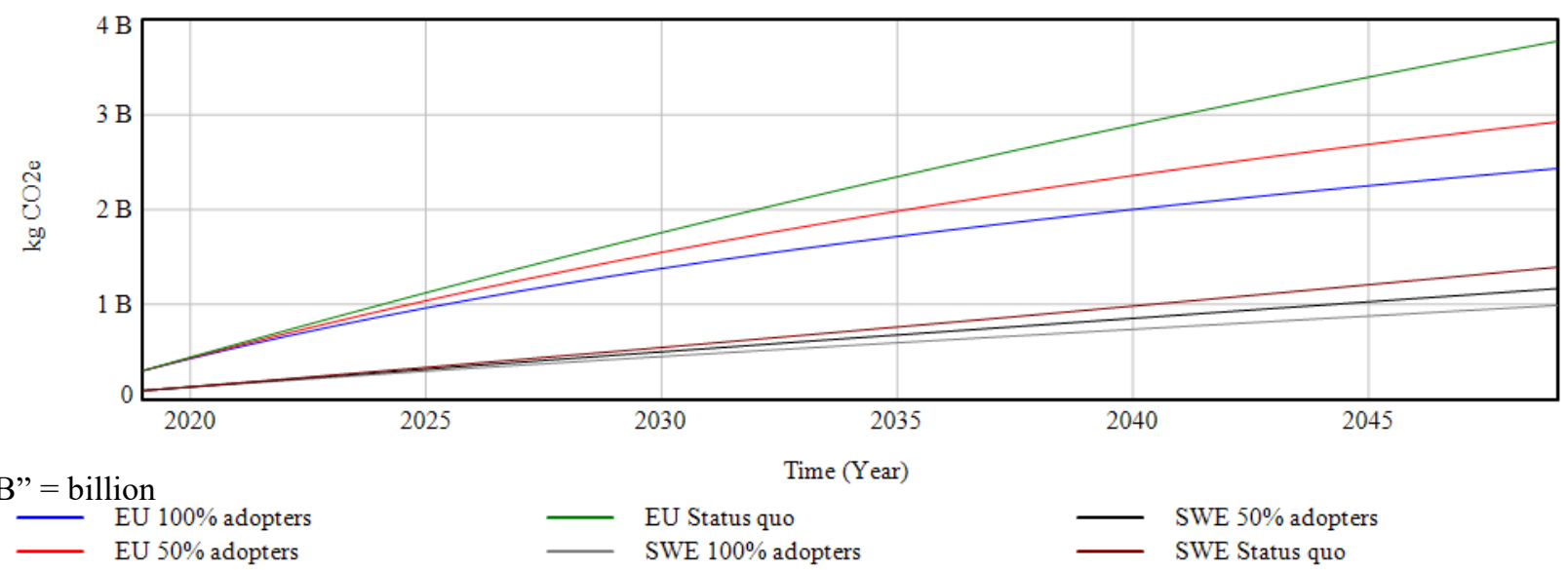

Figure 3. Total accumulated $\mathrm{CO}_{2}$ eq emissions of six scenarios from 2019-2049. The upper group of lines represents the three EU scenarios, the lower three lines the Swedish scenarios. The functional unit is the washing needs of the population living in multifamily housing expressed in wash cycles per household.

The accumulated numbers of produced machines differ quite a lot between the scenarios (see Table 2). In the "100\% become sharers" scenario, 2.04 million (EU: 2.92 million) fewer private machines and 93,000 (EU: 137,000) more shared WMs are produced than in status quo. This means the population can fulfil its 
needs with much fewer resources, as each shared machine replaces approximately 21.9 (EU: 21.3) privatelyowned WMs. This is mainly explained through the higher utilisation and longer lifetimes of shared WMs. Important to note is that shared washing machines are assumed to be $15 \%$ heavier, yet their use application significantly decreases total GHG emissions.

The average mass used in washing machines per household is calculated by adding up the accumulated numbers of private and shared machines divided by the total number of households. Note that the material composition was not considered in these calculations. For the Swedish scenarios, the average mass per household ranges from $47.2 \mathrm{~kg}$ to 108.2 over the three scenarios and in the European scenarios from 72.4 $\mathrm{kg}$ to 176.4. These high differences between the levels mainly go back to higher sharing rate in Sweden coupled with a faster population growth. Due to the different population growth forecasts (i.e. annual population growth of $0.7 \%$ for Sweden and $0.08 \%$ for EU average), the reference population in the Swedish scenarios grows from 2.2 million households to 2.69 and in the European scenarios from 2.2 to 2.25 until the end of the simulation period. Table 2 also presents how many households share a WM. It is interesting to see that only a few more households per shared machine are necessary to cause a notable drop in mass per household, i.e. material consumption. Note that in the EU average ownership levels are higher than in Sweden.

Table 2. Simulation results of the scenarios at the end of the simulations, year $=2049$.

\begin{tabular}{lccc||ccc}
\hline & \multicolumn{3}{c||}{ Sweden } & \multicolumn{3}{c}{ EU average } \\
\hline $\begin{array}{l}\text { Fraction of owners becoming } \\
\text { sharers }\end{array}$ & $\mathbf{1 0 0 \%}$ & $\mathbf{5 0 \%}$ & $\begin{array}{c}\text { Status } \\
\text { quo }\end{array}$ & $\mathbf{1 0 0 \%}$ & $\mathbf{5 0 \%}$ & $\begin{array}{c}\text { Status } \\
\text { quo }\end{array}$ \\
\hline $\begin{array}{l}\text { Accumulated CO } \\
\text { [billion kgCO emissions }\end{array}$ & 0.96 & 1.13 & 1.35 & 2.39 & 2.87 & 3.69 \\
\hline $\begin{array}{l}\text { Accumulated number of private } \\
\begin{array}{l}\text { WMs produced 2019-2049 } \\
\text { [million units] }\end{array}\end{array}$ & 1.10 & 1.91 & 3.14 & 1.62 & 2.61 & 4.54 \\
\hline $\begin{array}{l}\text { Accumulated number of shared } \\
\text { WMs produced 2019-2049 }\end{array}$ & 330 & 300 & 237 & 252 & 206 & 115 \\
[thousand units] & 47.2 & 71.4 & 108.2 & 72.4 & 107.6 & 176.4 \\
\hline $\begin{array}{l}\text { Mass per household } \\
\text { [kg per household] }\end{array}$ & 14.7 & 13.9 & 11.3 & 17.4 & 16.2 & 10.1 \\
\hline $\begin{array}{l}\text { Households per shared WM } \\
{[\text { household/machine] }}\end{array}$ & 635 & 718 & 817 & 700 & 805 & 992 \\
\hline $\begin{array}{l}\text { Accumulated detergent use } \\
\text { [million kg] }\end{array}$ & & & & & & \\
\hline
\end{tabular}

The accumulated detergent shows how large-scale application of more efficient machines can change the picture. Between the status quo and the $100 \%$ scenarios, there is a $22 \%$ difference for Sweden and $29 \%$ for the EU average.

The stocks of WMs are a mix of machines with different efficiencies, and the average of the stock is less efficient than the newest model. Figure 4 exemplifies this efficiency gap and the differences between the scenarios. Because the three scenarios have differing levels of utilisation (see "Households per machine" in 

increased utilisation of products accelerates the decrease of use-phase emissions.

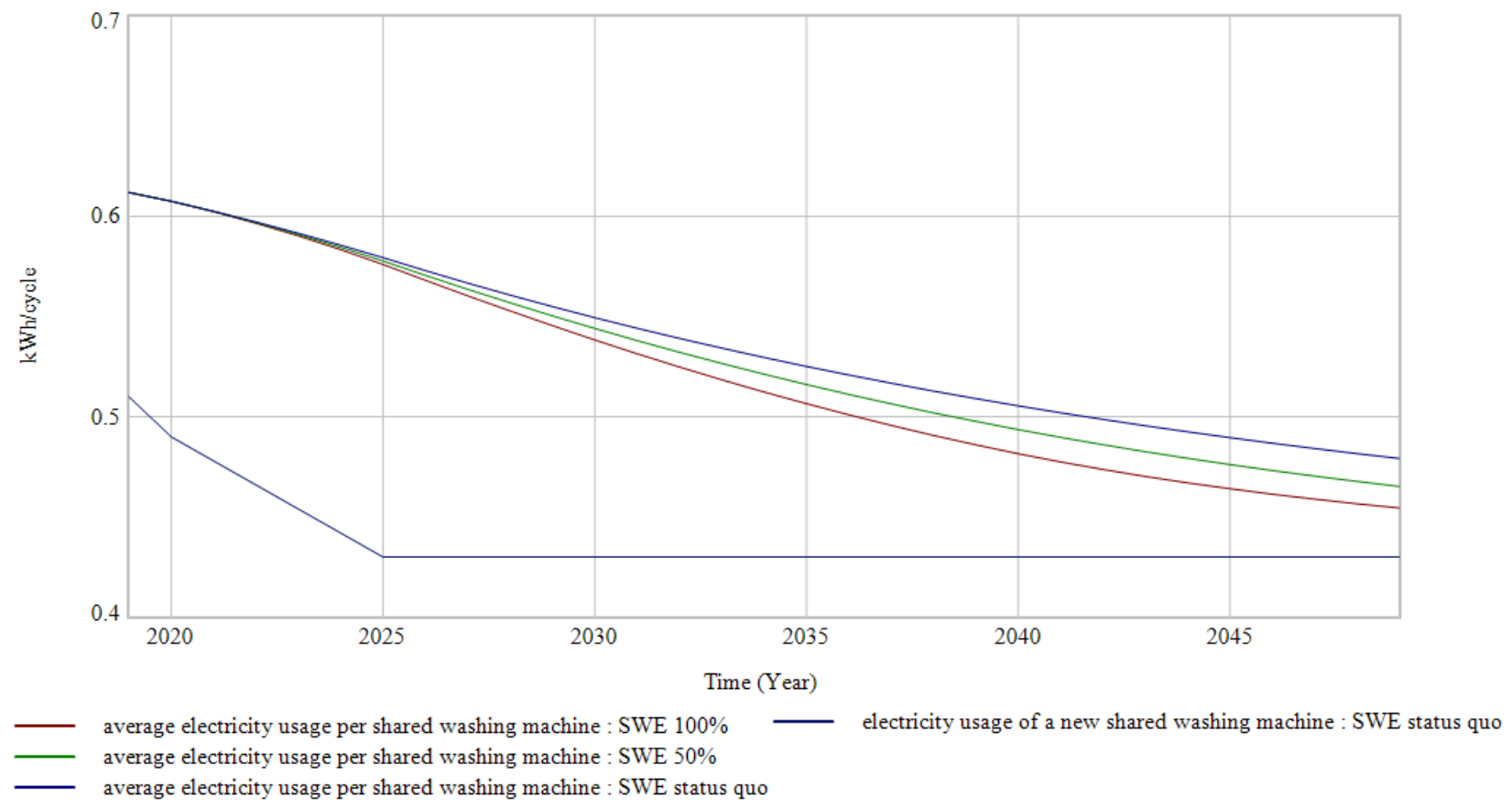

Figure 4. Energy efficiency gap between the newest WMs and the average WM in stock. The gap is the distance between the dark curve at the bottom and the coloured curves for each scenario.

The results in Table 1 help to answer the research question regarding the potential environmental effects of access-based consumption. Comparing the $100 \%$ scenario with the status quo scenario, we can see the difference in total emissions of $-29 \%$ for Sweden and $-35 \%$ for the EU, which shows the potential of sharing and is an argument for more political attention to the sharing economy (Maitre-Ekern \& Dalhammar, 2018). The number of accumulated private machines drops by $65 \%$ in Sweden and $64 \%$ in the EU average, whereas the additional accumulated number of shared machines is only 93,000 in Sweden and 137,000 in the EU, which translates to fairly high replacement rates. In Sweden, one shared WM replaces 21.9 privately-owned WMs, and in the European average, one shared WM replaces 21.3 private WMs.

There is an additional benefit of sharing: each WM needs approximately an area of $1 \mathrm{~m}^{2}$, which in the suggested scenarios translate into, millions of square meters saved. This gives tenants more space in their flats and a higher property value for real estate developers, or it enables smaller flats with associated reductions in resource use and emissions.

The impact of access-based consumption of energy using goods also depends on the geographic location. The differences in carbon intensities of national electricity mixes are a major concern for environmental impact assessments (Shahmohammadi et al., 2018). The results show that the EU average could not reach the low Swedish emissions levels, even if the whole population shared their WMs. This highlights the need to consider carbon intensities of electricity mixes when assessing policies for sharing economy.

The SD approach turned out useful to integrate diverse aspects from technology, behaviour and the environment. The analysed system exhibits multiple stocks, such as WMs and households, as well as internal feedback loops that affect overall resource use. SD allows an efficient way to deal with these system aspects. In addition, the visualisations offered by the SD tool, such as causal-loop diagrams and stock-and-flow diagrams, are a useful facilitator for system understanding and model development. 
The proposed SD model could be used for various populations across geographic areas. It might also be applied to other energy-using products like large household appliances and tools (Skjelvik et al., 2017). For the transition from owning to sharing, we chose a scenario approach where $0 \%, 50 \%$ or $100 \%$ of households shift from ownership- to the access-based behaviour without going into detail why households change their behaviour (Amasawa et al., 2018). For SD literature dealing with motivational aspects, we refer to (UlliBeer et al., 2010) or (Sterman, 2000), who develop dynamic models for behaviour change, including social norms and individual costs.

460 Influences from governmental policies were only indirectly part of the model, in the form of increasing energy performance (European Commission, 2010b) and the resulting decreasing energy use of washing machines. How to further operationalise policy aspects could be addressed in future work. Further, this study is a system analysis of a socio-technical system focussing on the environmental impact associated with sharing or individual ownership. Other systems that may be analysed in a similar manner are carsharing systems, bicycle-sharing systems, or other sharing systems for durables such as tools and clothes (Martin et al., 2019).

\section{Conclusions}

This work was motivated by the lack of studies on the transitional dynamics from owning to sharing and their effect on the environmental impacts in the extant literature. We analysed the case of washing machines in multi-family housing. Therefore, a system dynamics model was developed. The model includes aspects from population growth, designs of WMs, user behaviour, technological development and environmental impact assessment. It allowed to analyse the changes of product stocks as well as the related GHG emissions under the assumptions of certain user behaviours and national electricity carbon intensities. Model simulations used parametrisations for Sweden as well as the EU average.

The results showed that sharing behaviour for household laundry can decrease the related emissions significantly. The more households practice access-based consumption instead of owning WMs, the fewer WMs need to be produced overall resulting in less material consumption. Under the given assumptions regarding lower wash frequency and usage of more energy-efficient and longer-lasting machines, sharing resulted in GHG emission reductions of $29 \%$ with the Swedish parametrisation and $35 \%$ for the EU average. We regard the assumptions well-grounded and plausible and thus the overall results as rather robust.

We conclude that the rapid deployment of an energy-using technology that significantly improves its energy efficiency over the next years is valuable for reducing the increase of GHG emissions. In addition, with the decreasing significance of electricity (due to the mentioned efficiency improvements and the greening of energy mixes), emissions related to materials are of growing significance for energy-consuming products such as washing machines. This holds true also when the electricity consumption during the use phase exhibits a significantly lower carbon intensity and when energy use related to material processing, i.e., during production and EoL phases, has a higher carbon intensity.

The model has been applied in particular to the Swedish case. Sweden is a country with a relatively high sharing rate throughout the population. The country's energy mix also exhibits a very low energy carbon intensity. In order to put the Swedish case into perspective, a comparison to the EU average has shown that Sweden's relatively green electricity leads to lower laundry-related emissions than the EU average. These results might be interpreted as an argument for policies that support and facilitate shared laundry activities all across Europe in order to decrease GHG emissions.

A continuation of this work may be to make behaviour change an endogenous part of the model instead of treating it exogenously. Doing so, would be a progress towards answering the important question of "HOW TO make larger parts of population become sharers?" instead of "WHAT IF larger parts become sharers?". Future work on this issue might also take a broader stance on factors contributing to GHG emissions; e.g., technological developments apart from using heated water, which might bring benefits, especially in countries with a higher carbon intensity of the energy mix. 
501 This research is supported by the Circular European Economy Innovative Training Network (Circ€uit), funded by the European Commission under the Horizon 2020 Marie Skłodowska Curie Action 2016 (Grant Agreement number 721909) as well as by the Mistra REES (Resource Efficient and Effective Solutions) program (No. 2014/16) funded by Mistra (The Swedish Foundation for Strategic Environmental Research) and Areas of Advance Production at Chalmers University of Technology.

\section{References}

Ala-Mantila, S., Ottelin, J., Heinonen, J., \& Junnila, S. (2016). To each their own? The greenhouse gas impacts of intra-household sharing in different urban zones. Journal of Cleaner Production, 135, 356-367. doi:10.1016/j.jclepro.2016.05.156

Alborzi, F., Schmitz, A., \& Stamminger, R. (2017a). Effects of socio-demographic factors on laundry behaviours in Europe and their implications on sustainability. International Journal of Consumer Studies, 41(6), 671-684. doi:10.1111/ijcs.12380

Alborzi, F., Schmitz, A., \& Stamminger, R. (2017b). Long wash cycle duration as a potential for saving energy in laundry washing. Energy Efficiency, 10(4), 823-838. doi:10.1007/s12053-016-9486-z

Amasawa, E., Suzuki, Y., Moon, D., Nakatani, J., Sugiyama, H., \& Hirao, M. (2018). Designing Interventions for Behavioral Shifts toward Product Sharing: The Case of Laundry Activities in Japan. Sustainability, 10(8), 2687. doi:268710.3390/su10082687

Bardhi, F., \& Eckhardt, G. M. (2012). Access-Based Consumption: The Case of Car Sharing. Journal of consumer research, 39(4), 881-898. doi:10.1086/666376

Barthel, C., \& Götz, T. (2013). Technical background and design options to raise energy efficiency and reduce the envi-ronmental impact of domestic washing machines. Retrieved from http://www.bigee.net/media/filer public/2013/03/28/bigee domestic washing machines tech nical background 20130328.pdf

Barthel, C., \& Götz, T. (2017). The overall worldwide saving potential from domestic washing machines. Retrieved

from http://www.bigee.net/media/filer public/2013/03/28/bigee domestic washing machines worl dwide potential 20130328.pdf

Belk, R. (2014). You are what you can access: Sharing and collaborative consumption online. Journal of Business Research, 67(8), 1595-1600. doi:10.1016/j.jbusres.2013.10.001

Bocken, N. M. P., Mugge, R., Bom, C. A., \& Lemstra, H. J. (2018). Pay-per-use business models as a driver for sustainable consumption: Evidence from the case of HOMIE. Journal of Cleaner Production, 198, 498-510. doi:10.1016/j.jclepro.2018.07.043

Borg, L., \& Hogberg, L. (2014). Organization of Laundry Facility Types and Energy Use in Owner-Occupied Multi-Family Buildings in Sweden. Sustainability, 6(6), 3843-3860. doi:10.3390/su6063843

Bosch. (2018). Home | BlueMovement. Retrieved from https://www.bluemovement.nl/default.aspx?nr=11

Boyano, A., M, C., N, E., A, V., K, G., I, R., . . R, S. (2017). Ecodesign and Energy Label for Household Washing machines and washer dryers. Retrieved from http://susproc.jrc.ec.europa.eu/Washing machines and washer dryers/docs/JRC108604 2017 1117 wash prepstudy(6).pdf

Byers, S. S., Groth, J. C., \& Sakao, T. (2015). Using portfolio theory to improve resource efficiency of invested capital. Journal of Cleaner Production, 98, 156-165. doi:10.1016/j.jclepro.2013.11.014

Chen, T. D., \& Kockelman, K. M. (2016). Carsharing's life-cycle impacts on energy use and greenhouse gas emissions. Transportation Research Part D: Transport and Environment, 47, 276-284. doi:10.1016/j.trd.2016.05.012 
Cordella, M., Alfieri, A., \& Sanfelix, J. (2019). Analysis and development of a scoring system for repair and upgrade of products - Final report. Retrieved from Luxembourg:http://susproc.jrc.ec.europa.eu/ScoringSystemOnReparability/docs/JRC114337 rep ort repair scoring system final report v3.2 pubsy clean with identifiers.pdf

Davis, J. P., Eisenhardt, K. M., \& Bingham, C. B. (2007). Developing theory through simulation methods. Academy of Management Review, 32(2), 480-499. doi:doi.org/10.5465/amr.2007.24351453

EEA. (2017). Sweden GHG and energy 2017 country profile. Retrieved from Copenhagen:https://www.eea.europa.eu/themes/climate/trends-and-projections-in-

europe/trends-and-projections-in-europe-2017/country-profiles-greenhouse-gases-andenergy/sweden-ghg-and-energy-country-profile.pdf/view

EEA. (2019). European Union CO2 emission intensity 1990-2016. Retrieved 10/09/2019 https://www.eea.europa.eu/data-and-maps/daviz/co2-emission-intensity-5\#tabgooglechartid chart 11 filters=\%7B\%22rowFilters\%22\%3A\%7B\%7D\%3B $\% 22$ columnFilters $\% 22 \%$ 3A\%7B\%22pre config ugeo\%22\%3A\%5B\%22European\%20Union\%20(current\%20composition)\% 22\%5D\%7D\%7D

Electrolux. (2018). Front Load Washers - Electrolux Professional. Retrieved from https://professional.electrolux.com/commercial-laundry-equipment/front-load-washers/

Electrolux. (2019). A uniquely Swedish way of washing your clothes. Retrieved from https://www.electroluxgroup.com/en/a-uniquely-swedish-way-of-washing-your-clothes-29699/

European Commission. (2010a). Commission Delegated Regulation (EU) No 1061/2010 of 28 September 2010 supplementing Directive 2010/30/EU of the European Parliament and of the Council with regard to energy labelling of household washing machines.

European Commission. (2010b). Commission Regulation (EU) No. 1015/2010 of 10 November 2010 implementing Directive 2009/125/EC of the European Parliament and of the Council with regard to ecodesign requirements for household washing machines. Retrieved from https://eurlex.europa.eu/legal-content/EN/TXT/PDF/?uri=CELEX:32010R1015\&from=EN.

European Commission. (2016). A European agenda for the collaborative economy. (COM(2016) 356 final). Brussels.

European Commission. (2019). Commission Regulation (EU) C(2019) 2124 final of 1.10.2019 laying down ecodesign requirements for household washing machines and household washer-dryers pursuant to Directive 2009/125/EC of the European Parliament and of the Council, amending Commission Regulation (EC) No 1275/2008and repealing Commission Regulation (EU) No 1015/2010. Retrieved from https://ec.europa.eu/energy/sites/ener/files/documents/c-20192124 en act part1 v4.pdf.

Eurostat. (2015). Population projections at national level (2015-2080). Retrieved 10.03.2019 https://ec.europa.eu/eurostat/data/database?node code=proj

$\begin{array}{lllll}\text { Eurostat. (2018a). Household composition statistics. } & \text { Retrieved 10.03.2019 }\end{array}$ https://ec.europa.eu/eurostat/statistics-explained/index.php/Household composition statistics

Eurostat. (2018b). Persons who cannot afford a washing machine - EU-SILC survey. Retrieved 10.03.2019, from Eurostat

Eurostat. (2019a). Distribution of population by degree of urbanisation, dwelling type and income group EU-SILC survey. Retrieved 25.09.2019 https://ec.europa.eu/eurostat/web/main/home

Eurostat. (2019b). Waste statistics - electrical and electronic equipment Retrieved 01.01.2019 https://ec.europa.eu/eurostat/statistics-explained/index.php?title=Waste statistics electrical and electronic equipment\#Collection of WEEE by country

Huisman, J., Magalini, F., Kuehr, R., \& Khetriwal, D. (2018). Material Flows of the Home Appliance Industry - CECED. Retrieved from 
593

594

595

596

597

598

599

600

601

602

603

604

605

606

607

608

609

610

611

612

613

614

615

616

617

618

619

620

621

622

623

624

625

626

627

628

629

630

631

632

633

634

635

636

637

638

639

Jung, J., \& Koo, Y. (2018). Analyzing the Effects of Car Sharing Services on the Reduction of Greenhouse Gas (GHG) Emissions. Sustainability, 10(2), 539. doi:10.3390/su10020539

Kruschwitz, A., Karle, A., Schmitz, A., \& Stamminger, R. (2014). Consumer laundry practices in Germany. International Journal of Consumer Studies, 38(3), 265-277. doi:10.1111/ijcs.12091

Lund, K. (2009). Tvättstugan: en svensk historia: Nordiska museets förlag.

Maitre-Ekern, E., \& Dalhammar, C. (2016). Regulating planned obsolescence: A review of legal approaches to increase product durability and reparability in Europe. Review of European, Comparative and International Environmental Law, 25(3), 978-394. doi:10.1111/reel.12182

Maitre-Ekern, E., \& Dalhammar, C. (2018). Consumers in the Circular Economy: A Scandinavian Perspective. Paper presented at the Consumer Protection in a Circular Economy, Leuven.

Martin, C. J. (2016). The sharing economy: A pathway to sustainability or a nightmarish form of neoliberal capitalism? Ecological Economics, 121, 149-159. doi:10.1016/j.ecolecon.2015.11.027

Martin, M., Lazarevic, D., \& Gullström, C. (2019). Assessing the Environmental Potential of Collaborative Consumption: Peer-to-Peer Product Sharing in Hammarby Sjöstad, Sweden. Sustainability, 11(1), 190. doi:10.3390/su11010190

Mont, O., \& Plepys, A. (2007). System perspective on service provision: A case of community-based washing centres for households. International Journal of Public Affairs, 3, 130-151.

Mont, O. K. (2002). Clarifying the concept of product-service system. Journal of Cleaner Production, 10(3), 237-245. doi:10.1016/s0959-6526(01)00039-7

Morgan, E., Foxon, T. J., \& Tallontire, A. (2018). 'I prefer 30`?: Business strategies for influencing consumer laundry practices to reduce carbon emissions. Journal of Cleaner Production, 190, 234-250. doi:10.1016/j.jclepro.2018.04.117

Moro, A., \& Lonza, L. (2018). Electricity carbon intensity in European Member States: Impacts on GHG emissions of electric vehicles. Transp Res D Transp Environ, 64, 5-14. doi:10.1016/j.trd.2017.07.012

Pakula, C., \& Stamminger, R. (2010). Electricity and water consumption for laundry washing by washing machine worldwide. Energy Efficiency, 3(4), 365-382. doi:10.1007/s12053-009-9072-8

Parente, R. C., Geleilate, J. M. G., \& Rong, K. (2018). The Sharing Economy Globalization Phenomenon: A Research Agenda. Journal of International Management, 24(1), 52-64. doi:10.1016/j.intman.2017.10.001

Pettersen, I. N., Boks, C., \& Tukker, A. (2013). Framing the role of design in transformation of consumption practices: beyond the designer-product-user triad. International Journal of Technology Management, 63(1-2), 70-103. doi:10.1504/ljtm.2013.055580

Rahmandad, H., \& Sterman, J. D. (2012). Reporting guidelines for simulation-based research in social sciences. System Dynamics Review, 28(4), 396-411. doi:10.1002/sdr.1481

Retamal, M., \& Schandl, H. (2017). Dirty Laundry in Manila: Comparing Resource Consumption Practices for Individual and Shared Laundering. Journal of Industrial Ecology, 22(6), 1389-1401. doi:10.1111/jiec.12696

Saccani, N., Perona, M., \& Bacchetti, A. (2017). The total cost of ownership of durable consumer goods: A conceptual model and an empirical application. International Journal of Production Economics, 183, 1-13. doi:10.1016/j.ijpe.2016.09.021

Sakao, T., Wasserbaur, R., \& Mathieux, F. (2019). A methodological approach for manufacturers to enhance value-in-use of service-based offerings considering three dimensions of sustainability. Cirp Annals-Manufacturing Technology, 68(1), 33-36. doi:10.1016/j.cirp.2019.04.084

Sammer, K., \& Wüstenhagen, R. (2006). The influence of eco-labelling on consumer behaviour - results of a discrete choice analysis for washing machines. Business Strategy and the Environment, 15(3), 185-199. doi:10.1002/bse.522 
Schmitz, A., \& Stamminger, R. (2014). Usage behaviour and related energy consumption of European consumers for washing and drying. Energy Efficiency, 7(6), 937-954. doi:10.1007/s12053-0149268-4

Shahmohammadi, S., Steinmann, Z., Clavreul, J., Hendrickx, H., King, H., \& Huijbregts, M. A. J. (2018). Quantifying drivers of variability in life cycle greenhouse gas emissions of consumer products -a case study on laundry washing in Europe. The International Journal of Life Cycle Assessment, 23(10), 1940-1949. doi:10.1007/s11367-017-1426-4

Skjelvik, J. M., Erlandsen, A. M., \& Haavardsholm, O. (2017). Environmental impacts and potential of the sharing economy (Vol. 2017554): Nordic Council of Ministers.

SOU. (2017). Delningsekonomi på användarnas villkor. Statens offentliga utredningar 2017:26. Retrieved from https://www.riksdagen.se/sv/dokument-lagar/dokument/statens-offentligautredningar/delningsekonomi-pa-anvandarnas-villkor H5B326.

Stahel, W. R. (1994). The Utilization-Focused Service Economy - Resource Efficiency and Product-Life Extension. Greening of Industrial Ecosystems, 178-190.

Statistics Sweden. (2009). Housing and living environment 2006-07 (117). Retrieved from https://www.scb.se/sv /Hitta-statistik/Publiceringskalender/Visa-detaljeradinformation/?publobjid=8051

Statistics Sweden. (2019). Number of persons per household by region and type of housing. Year 2012 2018.

Retrieved

from: http://www.statistikdatabasen.scb.se/pxweb/en/ssd/START HE HE0111/HushallT29/\#

Sterman, J. (2000). Business Dynamics: Systems Thinking and Modeling for a Complex World: Irwin/McGraw-Hill.

Tecchio, P., Ardente, F., \& Mathieux, F. (2016). Analysis of durability, reusability and reparability Application to washing machines and dishwashers. Retrieved from http://publications.jrc.ec.europa.eu/repository/bitstream/JRC102632/lbna28042enn.pdf

Teece, D. J. (2010). Business Models, Business Strategy and Innovation. Long Range Planning, 43(2-3), $172-$ 194. doi:10.1016/j.Irp.2009.07.003

Ulli-Beer, S., Gassmann, F., Bosshardt, M., \& Wokaun, A. (2010). Generic structure to simulate acceptance dynamics. System Dynamics Review, 26(2), 89-116. doi:10.1002/sdr.440

Underwood, A., \& Fremstad, A. (2018). Does sharing backfire? A decomposition of household and urban economies in CO2 emissions. Energy Policy, 123, 404-413. doi:10.1016/j.enpol.2018.09.012

Zimmermann, J. P. (2009). End-use metering campaign in 400 households in sweden assessment of the potential electricity savings. Retrieved from https://www.energimyndigheten.se/globalassets/statistik/festis/elmatning-ibostader/final report.pdf 


\section{Appendix A: Stock-flow diagrams and lists of model equations organised 678 after sub-models}

679 A1 Population model: list of variables

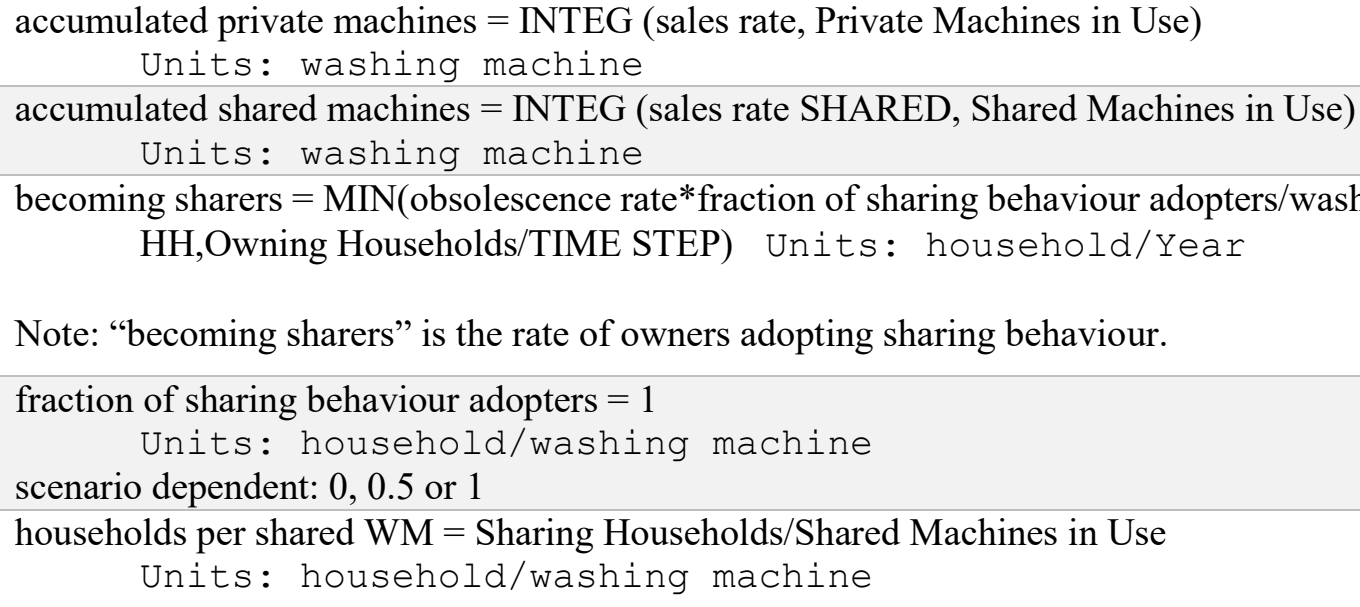

Note: "becoming sharers" is the rate of owners adopting sharing behaviour.

fraction of sharing behaviour adopters $=1$

Units: household/washing machine

scenario dependent: $0,0.5$ or 1

households per shared $\mathrm{WM}=$ Sharing Households/Shared Machines in Use

Units: household/washing machine

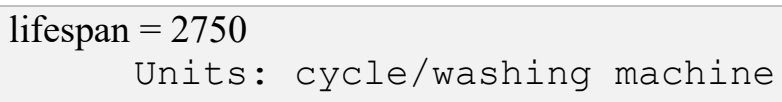

source: (Boyano et al., 2017)

lifespan shared $=30000$

Units: cycle/washing machine

source: (Electrolux, 2018)

new consumers sales rate $=$ owners increase rate*washing machines per $\mathrm{HH}$

Units: washing machine/Year

new sales rate shared $=$ (sharers increase rate+becoming sharers $) /$ recommended households per shared WM Units: washing machine/Year

obsolescence rate $=$ Private Machines in Use/lifespan*wash cycles per machine Units: washing machine/Year

obsolescence rate SHARED = Shared Machines in Use/lifespan shared*wash cycles per machine SHARED

Units: washing machine/Year

ownership rate $=$ Owning Households/(Owning Households+Sharing Households)

Units: dmnl

Owning Households = INTEG (owners increase rate-becoming sharers, 1.62e+006)

Units: household

EU: 1.62 million

SWE: 1.1 million

owners increase rate $=$ Owning Households*"population growth rate"

Units: household/Year

Note: "owners increase rate" is the increase of owners due to population growth.

Private Machines in Use = INTEG (sales rate-obsolescence rate, Owning Households)

Units: washing machine

population growth rate $=0.0008$

Units: 1/Year 
Note: "population growth rate" represents the expected growth rate of the general population.

recommended households per shared $\mathrm{WM}=25$

Units: household/washing machine

source:(Borg \& Hogberg, 2014)

Sharing Households $=$ Sharing Households $=$ INTEG $($ becoming sharers + sharers increase rate, $0.5764 \mathrm{e}+006$ )

Units: household

SWE: $1,100,000$

sales rate $=$ IF THEN ELSE(fraction of sharing behaviour adopters $<1$, (obsolescence rate* (1-fraction of sharing behaviour adopters))+new consumers sales rate, 0 )

Units: washing machine/Year

sales rate $\mathrm{SHARED}=$ new sales rate shared + obsolescence rate $\mathrm{SHARED}$

Units: washing machine/Year

sharers increase rate=Sharing Households*"population growth rate"

Units: household/Year

Shared Machines in Use $=$ INTEG (sales rate SHARED-obsolescence rate SHARED, Sharing Households/10)

Units: washing machine

washing machines per $\mathrm{HH}=1$

Units: washing machine/household 


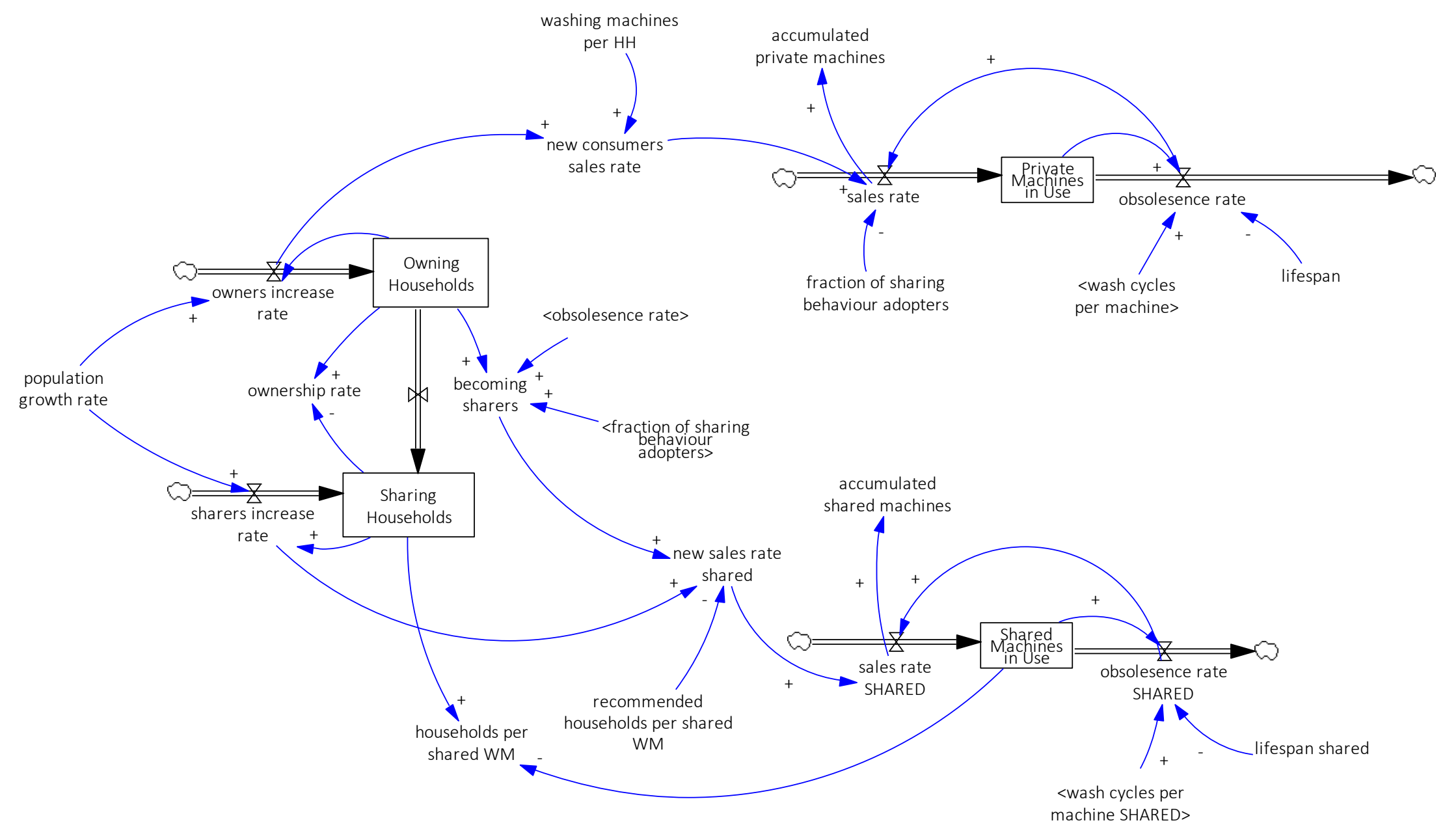


accumulated detergent use private $=$ INTEG (Detergent Usage Private, Detergent Usage Private) Units: $\mathrm{kg}$

accumulated detergent use SHARED = INTEG (Detergent Usage SHARED, Detergent Usage SHARED) Units: $\mathrm{kg}$

accumulated total detergent use $=$ accumulated detergent use private + accumulated detergent use shared Units: $\mathrm{kg}$

annual machine detergent use private $=$ detergent use per wash cycle private* wash cycles per machine Units: kg/ (washing machine*Year)

annual machine detergent use SHARED $=$ detergent use per wash cycle SHARED*wash cycles per machine SHARED

Units: kg/ (washing machine*Year)

annual machine electricity usage $=$ electricity usage of a new washing machine* wash cycles per machine Units: kWh/ (Year*washing machine)

annual machine electricity usage SHARED = electricity usage of a new shared washing machine*wash cycles per machine SHARED

Units: kWh/(washing machine*Year)

annual wash cycles per $\mathrm{HH}=$ individual wash frequency PRIVATE $*$ avg household size Units: cycle/(Year*household)

annual wash cycles per HH SHARED=individual wash frequency SHARED*avg household size Units: cycle/(Year*household)

average detergent usage per washing machine $=$ Detergent Usage Private/Private Machines in Use Units: kg/(washing machine*Year)

average detergent usage per washing machine SHARED = Detergent Usage SHARED /

Shared Machines in Use

Units: kg/washing machine/Year

average electricity usage per shared washing machine = Electricity Usage SHARED/Shared Machines in Use

Units: kWh/(washing machine*Year)

average electricity usage per washing machine $=$ Electricity Usage Private/Private Machines in Use Units: kWh/Year/washing machine

avg household size $=1.9$

Units: persons/household

source: (Statistics Sweden, 2019)

decrease in detergent usage PRIVATE = average detergent usage per washing machine * obsolescence rate

Units: $\mathrm{kg} /$ Year/Year

decrease in detergent usage SHARED $=$ average detergent usage per washing machine SHARED*obsolescence rate SHARED

Units: $\mathrm{kg} /$ Year/Year

decrease in electricity usage $=$ average electricity usage per washing machine*obsolescence rate Units: kWh/Year/Year

decrease in electricity usage SHARED $=$ average electricity usage per shared washing machine*obsolescence rate SHARED

Units: kWh/(Year*Year)

Detergent Usage Private $=$ INTEG (increase in detergent usage private-decrease in detergent usage PRIVATE, Private Machines in Use*annual machine detergent use private)

Units: kg/Year 
Detergent Usage SHARED = INTEG (increase in detergent usage SHARED-decrease in detergent usage SHARED, Shared Machines in Use*annual machine detergent use SHARED)

Units: $\mathrm{kg} /$ Year

detergent use per wash cycle private $=0.1$

Units: $\mathrm{kg} / \mathrm{cycle}$

source: (Kruschwitz et al., 2014)

detergent use per wash cycle SHARED $=0.08$

Units: $\mathrm{kg} /$ cycle

source: (Kruschwitz et al., 2014)

electricity usage of a new shared washing machine = energy usage over time SHARED(Time)

Units: kWh/cycle

electricity usage of a new washing machine = energy usage over time PRIVATE(Time)

Units: kWh/cycle

Electricity Usage Private = INTEG (increase in electricity usage-decrease in electricity usage, Private Machines in Use*annual machine electricity usage)

Units: kWh/Year

Electricity Usage SHARED = INTEG (increase in electricity usage SHARED-decrease in electricity usage SHARED, Shared Machines in Use*annual machine electricity usage SHARED)

Units: $\mathrm{kWh} /$ Year

energy usage over time PRIVATE ([(1990,0) - (2050,1.5)], (1990,1.48), (2010,1.1), (2015,1.04), (2020,0.97), (2025,0.91),(2030,0.85),(2035,0.79),(2040,0.73),(2045,0.67),(2050,0.61))

Units: kWh/cycle

source: (Boyano et al., 2017)

energy usage over time SHARED([(0,0)-(2050,10)],(1990,1.48), (2010,0.69),(2015,0.59), (2020,0.49),

$(2025,0.43),(2050,0.43))$

Units: kWh/cycle

source: (Boyano et al., 2017)

FINAL TIME $=2049$

Units: Year

The final simulation time.

increase in detergent usage private $=$ annual machine detergent use private*sales rate

Units: kg/ (Year*Year)

increase in detergent usage SHARED = sales rate SHARED*annual machine detergent use SHARED

Units: $\mathrm{kg} /$ Year/Year

increase in electricity usage $=$ annual machine electricity usage* sales rate

Units: kWh/Year/Year

increase in electricity usage SHARED = sales rate SHARED*annual machine electricity usage SHARED

Units: kWh/ (Year*Year)

individual wash frequency PRIVATE $=87.89$

Units: cycle/Year/person

EU: 87.89

SWE: 73.68

source: (Pakula \& Stamminger, 2010)

individual wash frequency SHARED $=52.63$

Units: cycle/Year/person

assuming 100 cycles per household $\rightarrow$ with 1.9 indiviudals per household: $52.63 * 1.9=100$

INITIAL TIME $=2019$

Units: Year

The initial time for the simulation. 
TIME STEP $=1$

Units: Year [0,?]

The time step for the simulation.

wash cycles per machine = annual wash cycles per $\mathrm{HH} /$ washing machines per $\mathrm{HH}$

Units: cycle/(washing machine*Year)

wash cycles per machine SHARED = annual wash cycles per HH SHARED*households per shared WM

Units: cycle/(washing machine*Year) 


\section{A4 Use phase model: stock-flow diagram}

688
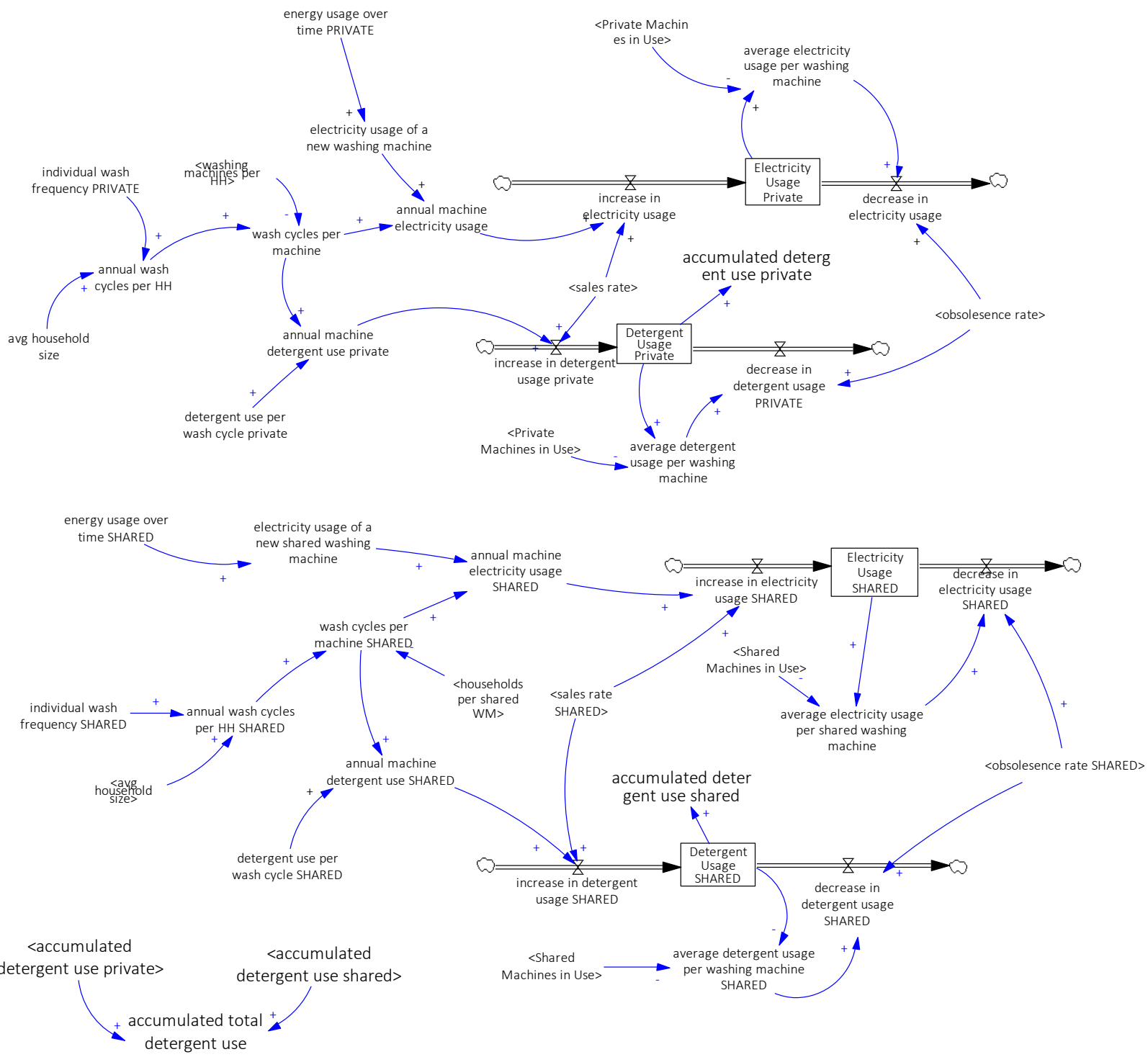
accumulated $\mathrm{CO} 2$ emissions $=\mathrm{CO} 2$ Use Phase PRIVATE $+\mathrm{CO} 2$ Use Phase SHARED $+\mathrm{CO} 2$ Production PRIVATE+CO2 Production SHARED-CO2 savings total

Units: $\mathrm{kg} \mathrm{CO} 2 \mathrm{e}$

$\mathrm{CO} 2$ manuf not electricity per unit PRIVATE $=52$

Units: $\mathrm{kg}$ CO2e/washing machine

source: (Boyano et al., 2017)

$\mathrm{CO} 2$ manuf not electricity per unit SHARED $=59.8$

Units: kg CO2e/washing machine

same as PRIVATE $+15 \%$ for more mass $\rightarrow 52 * 1.15=59.8$

$\mathrm{CO} 2$ per $\mathrm{kg}$ of detergent $=1.12$

Units: $\mathrm{kg} \mathrm{CO} 2 \mathrm{e} / \mathrm{kg}$

source: (Shahmohammadi et al., 2018)

$\mathrm{CO} 2$ Production PRIVATE $=$ INTEG $(\mathrm{CO} 2$ rate for production PRIVATE, Private Machines in Use* $(\mathrm{CO} 2$ manuf not electricity per unit PRIVATE+electricity usage production PRIVATE

*Electricity Carbon Intensity))

Units: $\mathrm{kg} \mathrm{CO} e$

$\mathrm{CO} 2$ Production SHARED $=$ INTEG $(\mathrm{CO} 2$ rate for production SHARED, Shared Machines in Use*(Electricity Carbon Intensity*electricity usage production SHARED+CO2 manuf not electricity per unit SHARED))

Units: $\mathrm{kg} \mathrm{CO} 2 \mathrm{e}$

$\mathrm{CO} 2$ rate for detergent use $=\mathrm{CO} 2$ per kg of detergent * Detergent Usage Private Units: $\mathrm{kg}$ CO2e/Year

$\mathrm{CO} 2$ rate for detergent use SHARED = Detergent Usage SHARED*CO2 per kg of detergent Units: kg CO2e/Year

$\mathrm{CO} 2$ rate for energy supply $=$ Electricity Carbon Intensity*Electricity Usage Private Units: kg CO2e/Year

$\mathrm{CO} 2$ rate for energy supply SHARED = Electricity Usage SHARED*Electricity Carbon Intensity Units: kg CO2e/Year

$\mathrm{CO} 2$ rate for production PRIVATE $=$ sales rate*(electricity usage production PRIVATE*Electricity Carbon Intensity $+\mathrm{CO} 2$ manuf not electricity per unit PRIVATE)

Units: kg CO2e/Year

$\mathrm{CO} 2$ rate for production $\mathrm{SHARED}=$ sales rate SHARED*(electricity usage production SHARED*Electricity Carbon Intensity+CO2 manuf not electricity per unit SHARED) Units: $\mathrm{kg}$ CO2e/Year

$\mathrm{CO} 2$ savings PRIVATE $=$ (accumulated private machines-Private Machines in Use)*WM collection rate * (recycling saving factor material+recycling saving factor material+recycling saving factor electricity*Electricity Carbon Intensity)

Units: $\mathrm{kg} \mathrm{CO} 2 \mathrm{e}$

CO2 savings SHARED = (accumulated shared machines-Shared Machines in Use)*(recycling saving factor material+recycling saving factor electricity*Electricity Carbon Intensity)*1.15 Units: $\mathrm{kg} \mathrm{CO} 2 \mathrm{e}$

$\mathrm{CO} 2$ savings total $=\mathrm{CO} 2$ savings $\mathrm{PRIVATE}+\mathrm{CO} 2$ savings $\mathrm{SHARED}$ Units: kg $\mathrm{CO} 2 \mathrm{e}$

$\mathrm{CO} 2$ Use Phase PRIVATE $=$ INTEG $(\mathrm{CO} 2$ rate for detergent use $+\mathrm{CO} 2$ rate for energy supply,0) Units: $\mathrm{kg} \mathrm{CO} e$

CO2 Use Phase SHARED = INTEG (CO2 rate for detergent use SHARED+CO2 rate for energy supply SHARED,0) 
Units: $\mathrm{kg} \mathrm{CO} 2 \mathrm{e}$

Electricity Carbon Intensity $=0.51542 * \mathrm{EXP}(-0.018 *($ Time/TIME STEP-1990))

Units: $\mathrm{kg} \mathrm{CO} 2 \mathrm{e} / \mathrm{kWh}$

EU: $0.51542 * \operatorname{EXP}(-0.018 *($ Time/TIME STEP-1990)) => extrapolated trend from source: (EEA, 2019)

SWE: 0.047 (assumed constant) (Moro \& Lonza, 2018)

electricity usage production PRIVATE $=382$

Units: kWh/washing machine

source: (Boyano et al., 2017)

electricity usage production SHARED $=1372$

Units: kWh/washing machine

source: (Boyano et al., 2017)

recycling saving factor electricity $=24.2$

Units: kWh/washing machine

source: (Boyano et al., 2017)

recycling saving factor material $=21.5$

Units: kg CO2e/washing machine

source: (Boyano et al., 2017)

relative use phase emissions $=(\mathrm{CO} 2$ Use Phase PRIVATE $+\mathrm{CO} 2$ Use Phase SHARED $) /$ Total CO2 emissions

$\mathrm{WM}$ collection rate $=0.41$

Units: dmnl

EU:0.41

SWE: 0.55

source: (Eurostat, 2019b) 
A6 Emissions model: stock-flow diagram

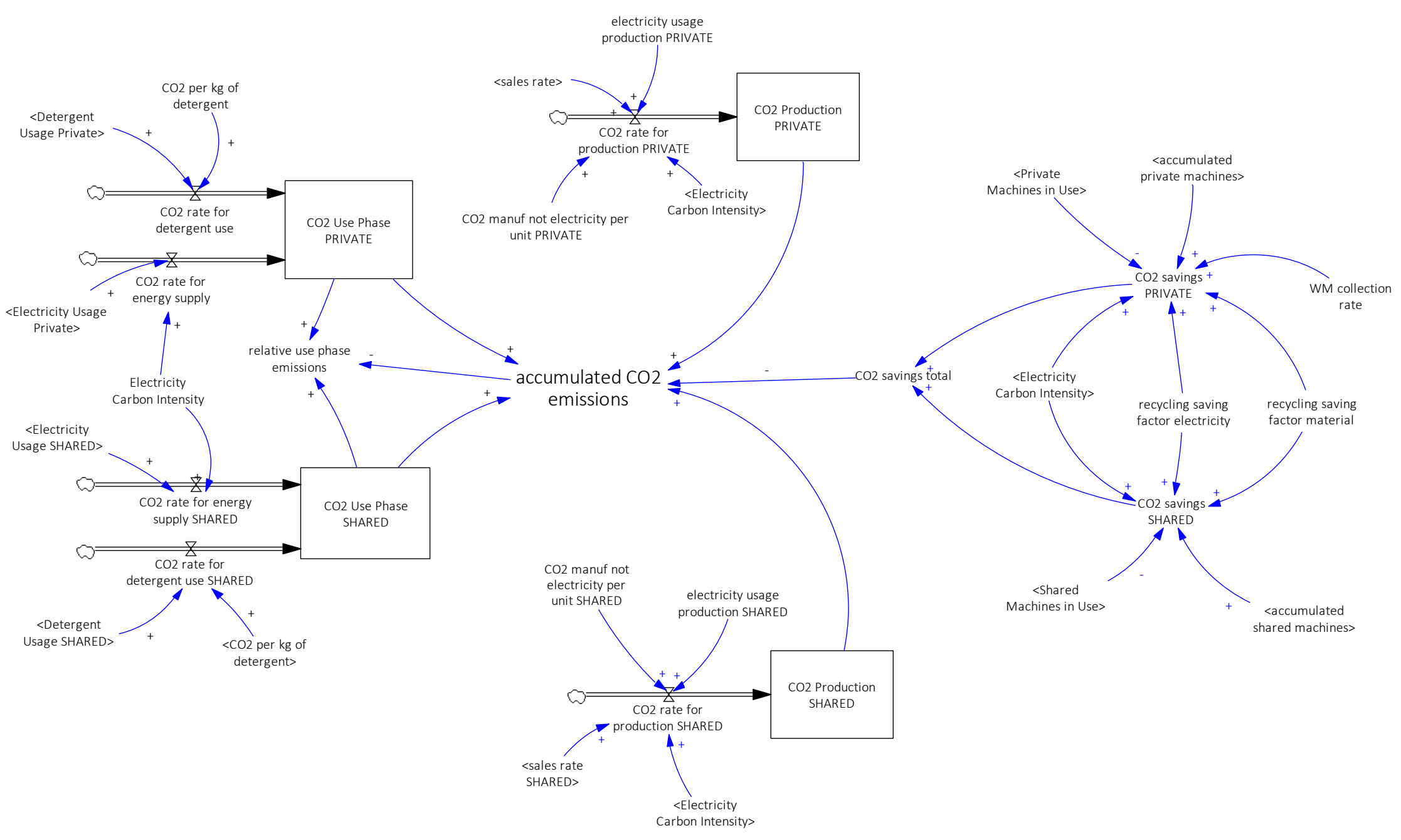




\section{Appendix B: Washing machine ownership calculation for the entire EU}

\begin{tabular}{|c|c|c|c|}
\hline EU country & Ownership* [\%] & Population [million] & Populaton x Ownership [million] \\
\hline Austria & 0.95 & 8.9 & 8.455 \\
\hline Belgium & 0.95 & 11.5 & 10.925 \\
\hline Bulgaria & 0.44 & 7 & 3.08 \\
\hline Croatia & 0.65 & 4.1 & 2.665 \\
\hline Cyprus & 0.95 & 0.9 & 0.855 \\
\hline Czech Republic & 0.6 & 10.6 & 6.36 \\
\hline Denmark & 0.79 & 5.8 & 4.582 \\
\hline Estonia & 0.78 & 1.3 & 1.014 \\
\hline Finland & 0.89 & 5.5 & 4.895 \\
\hline France & 0.97 & 67.3 & 65.281 \\
\hline Greece & 0.95 & 10.8 & 10.26 \\
\hline Germany & 0.95 & 82.9 & 78.755 \\
\hline Hungary & 0.7 & 9.8 & 6.86 \\
\hline Ireland & 0.95 & 4.9 & 4.655 \\
\hline Italy & 0.95 & 60.4 & 57.38 \\
\hline Latvia & 0.65 & 1.9 & 1.235 \\
\hline Lithuania & 0.82 & 2.8 & 2.296 \\
\hline Luxembourg & 0.95 & 0.6 & 0.57 \\
\hline Malta & 0.82 & 0.5 & 0.41 \\
\hline Netherlands & 0.98 & 17.3 & 16.954 \\
\hline Norway & 0.82 & 5.3 & 4.346 \\
\hline Poland & 0.76 & 38.4 & 29.184 \\
\hline Portugal & 0.85 & 10.3 & 8.755 \\
\hline Romania & 0.51 & 19.5 & 9.945 \\
\hline Slovakia & 0.6 & 5.5 & 3.3 \\
\hline Slovenia & 0.98 & 2.1 & 2.058 \\
\hline Spain & 0.95 & 46.7 & 44.365 \\
\hline Sweden & 0.83 & 10.2 & 8.466 \\
\hline UK & 0.93 & 66 & 61.38 \\
\hline \multicolumn{2}{|c|}{ total EU population } & 518.8 & \\
\hline \multicolumn{2}{|c|}{ "owning" population" } & & 459.286 \\
\hline
\end{tabular}

* Data from: Pakula, C., \& Stamminger, R. (2010). Electricity and water consumption for laundry washing by washing machine worldwide.

Energy Efficiency, 3(4), 365-382. doi:10.1007/s12053-009-9072-8

EU: Population living in flats*: $\sim 42 \%$ population living in houses: $58 \%$

We assume all households living in houses own their washing machine.

If $89 \%$ of the households in the EU (own calculations) own their WMs, this means that $58 \%$ are in houses and $31 \%$ are in flats.

If $36 \%$ of the owned WMs are in flats, and if $42 \%$ of the households live in flats, then $31 \% / 42 \%=73.8 \%$ of flat households own a $\mathrm{WM}$ in the EU, whereas the rest $(26.2 \%)$ is sharing.

\section{Dwelling type}
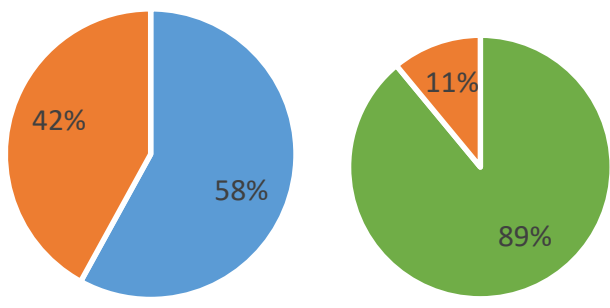

house flats

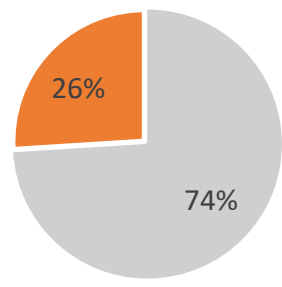

\section{Total WM WM ownership ownership of flats}

- Owners 